\title{
MONTE CARLO BASED LIGHTNING RISK ASSESSMENT IN OIL PLANT TANK FARMS
}

\author{
A. Borghetti ${ }^{1}$, V. Cozzani ${ }^{1}$, C. Mazzetti ${ }^{2}$, C.A. Nucci $^{1}$, M. Paolone ${ }^{1}$, E. Renni ${ }^{1}$ \\ ${ }^{1}$ University of Bologna, Italy - \{alberto.borghetti; valerio.cozzani; carloalberto.nucci; mario.paolone; \\ elisabetta.renni\}@unibo.it \\ ${ }^{2}$ University of Rome "La Sapienza”, Italy - carlo.mazzetti@uniroma1.it
}

\begin{abstract}
The paper aims at illustrating a procedure for the lightning risk assessment of industrial oil process plants. The procedure is based on the use of the Monte Carlo method and applies to each event both a lightning attachment criterion and a damage calculation model. In particular, for the case of oil tanks, the model calculates the expected annual number of damages associated to the metal melting due to direct lightning events. The paper also presents and discusses an application example of the proposed procedure.
\end{abstract}

\section{INTRODUCTION}

Storage facilities, which may be at chemical plants or in other storage terminals, contain large quantities of chemicals. The prevention of loss in storage is therefore extremely important. Lightning strokes that hit storage or process vessels containing flammable materials can cause devastating accidents. In recent years, several accidents have occurred where lightning has struck facilities handling flammable substances, resulting in explosions and fires $[1,2]$.

The assessment of the risk associated to lightning events is a typical calculation for industrial process plants (e.g. [3-7]). Such an assessment is of particular importance for the case of chemical and process industry, where it might be compulsory by legislation, at least in most European countries.

The calculation is usually carried out by using probabilistic approaches in which the annual number of influencing flashes, the probability of damage by one of the influencing flashes and the mean amount of consequential loss due to one flash need to be evaluated (e.g. $[3,8,9])$.

With reference to the case of an oil tank plant, the probability of damage appears to be mainly related to the following lightning parameters: current peak value $I_{\mathrm{p}}$, maximum $\mathrm{d} i / \mathrm{d} t$ and total charge $Q$. These parameter are associated with the appearance of hot spots in the metallic structure of the tanks, of induced voltages and with melting phenomena, as shown by specific numerical models and experimental tests (e.g. [10,11]).

Moreover, the current peak value plays a decisive role on the usual attachment models [12] and therefore is also taken into account in order to evaluate the probability of direct strokes to a structure.

The paper presents a statistical procedure that is based on Monte Carlo simulations and applies the electrogeometric model and a damage calculation model to the metal melting of the oil tanks due to direct strikes.

In this paper, the damage model is limited to comparison between the expected melting caused the thermal heating and the shell thickness in order to provide a first evaluation of the annual expected number of punctures for each of the tanks. The developed procedure appears to be able to incorporate different or more accurate damage models without a significant change of its structure.

The structure of the paper is the following: section 2 illustrates the typical layout of oil tank farms, section 3 describes the proposed procedure, section 4 presents the application example to a specific set of oil tanks, section 5 illustrates the effects of the presence of protection rods and wires and section 6 is devoted to the conclusions.

\section{OIL PLANT TANK FARMS}

The main types of storage tanks and vessels for liquids and liquefied gases are (1) atmospheric and low pressure storage tanks, (2) pressurized storage vessels, and (3) refrigerated (cryogenic) storage tanks.

For each type of storage tanks there are standard geometries that correlates the volume capacity with the dimensions (diameter and height for the cylindrical vessels).

A number of standards and codes may be applied to the storage of petroleum products and flammable liquids. Standards and codes include API Std 620 [13] and Std 650 [14], NPFA 30 [15] and the Refining Safety Code of the IP [16].

For liquid storage, it is common to segregate the liquids stored according to their class, related to the flash 
point value. There are a large number of standards, codes of practice and other publications which give minimum safe separation distances. The guidance available [17] relates mainly to separation distances for storage, either of petroleum products, of flammable liquids, of liquefied petroleum gas (LPG) or of liquefied flammable gas (LFG).

The layout of tanks, as distinct from their spacing, should always take into consideration the accessibility needed for fire-fighting and the potential value of a storage tank farm in providing a buffer area between process plant and public roads, houses, etc., for safety reasons. The location of tanks relevant to process units must be such as to ensure maximum safety from possible incidents. The distance between individual tanks in the group is mainly governed by constructional and operating convenience, unless safety issues are relevant. Tank distances are however never lower than $2 \mathrm{~m}$.

\section{METHODOLOGY FOR THE CALCULATION OF THE LIGHTNING STRIKE PROBABILITY AND DAMAGE}

\subsection{Lightning strike probability calculation}

The paper adopts the Monte Carlo method, already proposed for the evaluation of the assessment of overhead line indirect lightning performance [18], as it allows a straightforward comparison between results obtained by using different statistics of lightning parameters, different lightning attachment models and different damage calculation methods in order to evaluate direct and indirect lightning effects.

In what follows, we describe the steps of the proposed numerical procedure for the calculation of the lightning strike probability of oil tanks.

a. A large number of events $n_{\text {tot }}$ is randomly generated, each event $i$ being characterized by five parameters: lightning current amplitude $I_{p}$ and front time $t_{\mathrm{f}}$, impulse charge $Q$ and stroke location coordinates $x$ and $y$. Parameter $I_{\mathrm{p}}, t_{\mathrm{f}}$ and $Q$ of the randomly generated events are assumed to follow the Cigré log-normal probability distributions $[19,20]$ for downward negative first strokes ${ }^{1}$. The stroke locations are assumed to be uniformly distributed within an area $A$ that contains the entire oil tank farm and it is wide enough in order to take into account all the events that may hit a tank.

b. For each of the randomly generated events $i$, the

\footnotetext{
${ }^{1}$ Namely, median value $\mu_{I p}{ }^{\prime}=61.1 \mathrm{kA}$ and standard deviation of the natural logarithm $\sigma_{I p}{ }^{\prime}=1.33$ for $I_{\mathrm{p}} \leq 20 \mathrm{kA}, \mu_{I p}{ }^{\prime \prime}=33.3 \mathrm{kA}$ and $\sigma_{I p}{ }^{\prime \prime}=0.605$ for $I_{\mathrm{p}}>20 \mathrm{kA}, \mu_{t f}=3.83 \mu \mathrm{s}$ and $\sigma_{t f}=0.553$ for $t_{f}$, $\mu_{Q}=4.65 \mathrm{As}$ and $\sigma_{Q}=0.875$ for $Q$, with a correlation coefficient between the distributions of $I_{\mathrm{p}}$ and $t_{\mathrm{f}}$ equal to 0.45 and between $I_{\mathrm{p}}$ and $Q$ equal to 0.77 .
}

procedure determines whether the specific event is collected by one of the structures that compose the oil farm. Each oil tank $t$ has been represented by a solid cylinder with polygonal cross section and with flat roof. As a first approximation, the lightning incidence is assessed by means of the electrogeometric lightning incidence model (EGM) adopted by IEEE Std. (e.g. [21] $)^{2}$. Lightning event $i$ is considered a direct lightning to the oil tank $t$ if in its vertical approaching to ground it encounters a point characterized by a distance from the nearest point $k$ that belongs to the upper corner of tank $t$ lower than the so called critical distance and this condition has not been previously met for any other structure or the ground itself. The typical equation for the calculation of the critical distance to the corner points $r_{\mathrm{s}}$ is:

$$
r_{s}=10 I_{\mathrm{p}}^{0.65}
$$

For the critical distance $r_{\mathrm{g}}$ to flat surfaces (ground and roofs) we adopt

$$
r_{g}=0.9 r_{\mathrm{s}}
$$

Several inception models have been presented in the literature, more physically based than the electrogeometrical one, adopted in this study.

c. If $n(t)$ is the number of events that result to be collected by tank $t$, the expected annual number of direct strokes to tank $t$ is obtained from the following expression:

$$
F_{d}=\frac{n(t)}{n_{t o t}} N_{g} A
$$

where $N_{\mathrm{g}}$ is the annual ground flash density (in $\mathrm{km}^{-1}$ $\left.\mathrm{yr}^{-1}\right)$.

d. For each of oil tank $t$, each direct lightning event is characterized by a specific current amplitude and charge. This set of events is then used for the application of the damage model, as described in section 3.3 .

\subsection{Application of the procedure for the calculation of the strike annual frequency calculation to a cylindrical structure}

As vertical cylindrical steel tanks, with fixed or floating roof, are often used at petroleum product storage centers and refineries, we illustrate here the application of the procedure for the calculation of the annual number of direct strikes to a cylindrical structure.

\footnotetext{
2 Other, more accurate, models for exposure of grounded objects to direct lightning strokes have been proposed in the literature and may be implemented in the proposed procedure (e.g., [22-25]). An analysis of the striking distance to ground is reported in [26].
} 
We consider three different tank sizes: a tank with a base diameter equal to $15 \mathrm{~m}$ and height equal to $6 \mathrm{~m}$ (Tank 1), a tank with diameter equal to $10.7 \mathrm{~m}$ and height equal to $9 \mathrm{~m}$ (Tank 2) and a tank with both diameter and height equal to $7.5 \mathrm{~m}$ (Tank 3). By using a set of 500000 randomly generated events, Fig. 1 shows the perspective stroke locations (i.e. stroke locations at ground without the presence of the tank) relevant to the lightning events that hit Tank 1 according to the adopted EGM (the figures relevant to Tank 2 and Tank 3 are similar).

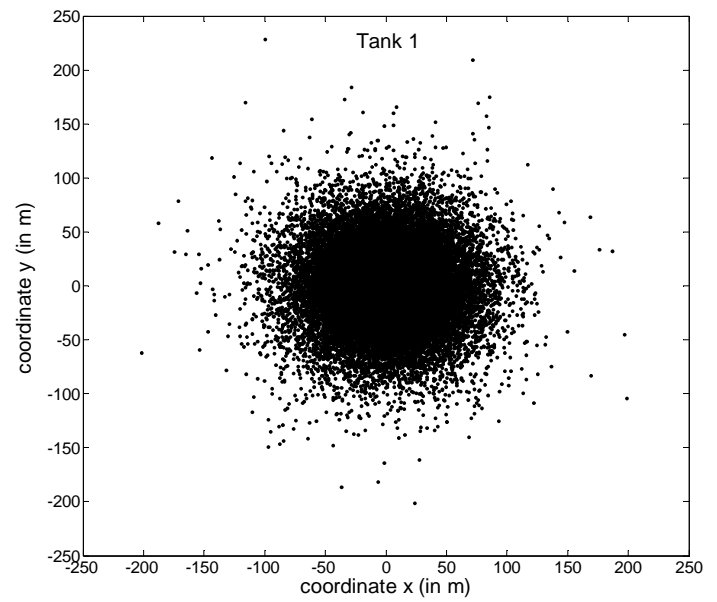

Fig. 1 - Top view of the perspective stroke locations of the events that strike Tank 1.

For isolated structures, often the expected annual number of direct strikes $F_{\mathrm{d}}$ is expressed by the product between the flash density $N_{\mathrm{g}}$ and a collection area $A_{\mathrm{d}}$ of the structure (e.g. IEC standard 62305-2 [27]). Table I shows the values of the annual frequency for Tank 1 , Tank 2, and Tank 3 calculated by using the Monte Carlo approach for the case of $N_{\mathrm{g}}=3$ flashes $/ \mathrm{km} / \mathrm{yr}$ and the corresponding $A_{\mathrm{d}}$ values.

Table I - Annual number of direct strokes $F_{\mathrm{d}}$ and collection area $A_{\mathrm{d}}$ values calculated for the case of Tank 1 and Tank,

\begin{tabular}{|l|c|c|c|}
\multicolumn{4}{|c}{ assuming $N_{\mathrm{g}}=3$ flashes/km/yr. } \\
\hline $\begin{array}{l}\text { Tank } \\
\text { no. }\end{array}$ & $\begin{array}{c}F_{\mathrm{d}} \\
\left.\text { (strokes } / \mathrm{km}^{2} / \text { year }\right)\end{array}$ & $\begin{array}{c}\text { Calculated } \\
A_{\mathrm{d}} \text { value } \\
\left(\mathrm{km}^{2}\right)\end{array}$ & $\begin{array}{c}A_{\mathrm{d}} \text { value } \\
\text { according to } \\
{[27]}\end{array}$ \\
\hline 1 & 0.042 & 0.014 & 0.002 \\
\hline 2 & 0.045 & 0.015 & 0.003 \\
\hline 3 & 0.040 & 0.013 & 0.002 \\
\hline
\end{tabular}

Table I also shows the $A_{\mathrm{d}}$ values obtained by using the criterion proposed in [27], namely the area of the cylinder base augmented by a band large three times the value of the cylinder height. These $A_{\mathrm{d}}$ values are significantly lower than those calculated. The difference reduces if higher cylinders are considered and similar results would be obtained for a cylinder height of $27 \mathrm{~m}\left(A_{\mathrm{d}}=0.025 \mathrm{~km}^{2}\right.$ for a diameter equal to $15 \mathrm{~m}, A_{\mathrm{d}}=0.024 \mathrm{~km}^{2}$ for a diameter equal to $10.7 \mathrm{~m}$, and $A_{\mathrm{d}}=0.023 \mathrm{~km}^{2}$ for a diameter equal to $7.5 \mathrm{~m}$ ). For higher height values the calculated values are lower than those obtained by applying the criterion of standard [27]. By varying the diameter value, with a constant height equal to $27 \mathrm{~m}$, the variations of the calculated $A_{\mathrm{d}}$ values are in agreement with those of standard [27].

\subsection{Damage calculation}

For each of the direct lightning events, the damage calculation model is applied to determine whether the event $i$ is able to produce a dangerous metal melting of the oil tank $t$. Therefore, for each oil tank it is possible to express the risk of damage.

The main effects of a direct stroke to a metallic storage tank are the appearance of hot spots on the rear surface and the melting process.

Thermal effects linked with lightning current are relevant to the resistive heating caused by the circulation of an electric current flowing through the resistance of the conductor. Thermal effects are also relevant to the heat generated in the root of the arcs at the attachment point and in all the isolated parts involved in arc development (e.g. spark gaps). An analytical approach to evaluate the temperature rise of conductors subjected to the flow of a lightning current is presented in IEC standard [27].

In a lightning discharge, the high specific energy phases of the lightning flash are too short in duration for any heat generated in the structure to be dispersed significantly. The phenomenon is therefore to be considered adiabatic and the temperature of the conductors can be evaluated as follows:

$$
\theta-\theta_{0}=\frac{1}{\alpha}\left[\exp \frac{\frac{W}{R} \alpha \rho_{0}}{q^{2} \gamma c_{w}}-1\right]
$$

where:

$\theta-\theta_{0} \quad$ temperature rise of the conductors $\left({ }^{\circ} \mathrm{K}\right)$;

$\alpha \quad$ temperature coefficient of the resistance $\left(1 /{ }^{\circ} \mathrm{K}\right)$;

$W / R \quad$ specific energy of the current impulse $(\mathrm{J} / \Omega)$;

$\rho_{0} \quad$ specific ohmic resistance of the conductor at ambient temperature $(\Omega \mathrm{m})$;

$q \quad$ cross-section area of the conductor $\left(\mathrm{m}^{2}\right)$;

$\gamma \quad$ material density $\left(\mathrm{kg} / \mathrm{m}^{3}\right)$;

$C_{w} \quad$ thermal capacity $\left(\mathrm{J} / \mathrm{kg}{ }^{\circ} \mathrm{K}\right)$.

Attachment point thermal damage can be observed on all components of an equipment item on which an arc development takes place. Material melting and erosion can occur at the attachment point. In fact, in the arc root area there is a large thermal input from the arc root itself, as well as a production of heating due to the high current densities. Most of the thermal energy is generated at or very close to the surface of the metal. The heat generated 
in the immediate root area is in excess of that which can be absorbed into the metal by conduction and the excess is irradiated or lost in melting or vaporizing of metal. The severity of the process is linked to the current amplitude and to the duration.

Several theoretical models have been developed for the calculation of thermal effects on metal surfaces at the attachment point of a lightning channel. For sake of simplicity, IEC standard [27] reports only the anode-orcathode voltage drop model. The application of this model is particularly effective for thin metal skins. In all cases, it gives conservative results as it postulates that all the energy injected in the lightning attachment point is used to melt or vaporize conductor material, neglecting the heat diffusion within the metal. Other models introduce the dependence of the lightning attachment point damage on the duration of the current impulse.

The energy input $W$ at the arc root is assumed as given by the anode/cathode voltage drop $u_{\mathrm{a}, \mathrm{c}}$ multiplied by the charge $Q$ of the lightning current:

$$
W=\int u_{a, c} i d t=u_{a, c} \int i d t=u_{a, c} Q
$$

As $u_{\mathrm{a}, \mathrm{c}}$ is fairly constant in the current range considered here, the charge of the lightning current $(Q)$ is primarily responsible for the energy conversion in the arc root. The anode-or-cathode voltage drop $u_{\mathrm{a}, \mathrm{c}}$ has a value of a few tens of volts. A simplified approach assumes that all of the energy developed at the arc root is used only for melting. Equation (6) uses this assumption and leads to an overestimate of the melted volume:

$$
V=\frac{u_{a, c} Q}{\gamma} \frac{1}{C_{w}\left(\theta_{s}-\theta_{u}\right)+c_{s}}
$$

where

$V$ is the volume of metal melted $\left(\mathrm{m}^{3}\right)$;

$u_{\mathrm{a}, \mathrm{c}}$ is the anode-or-cathode voltage drop (assumed as constant) (V);

$Q$ is the charge of the lightning current (C);

$\gamma$ is the material density $\left(\mathrm{kg} / \mathrm{m}^{3}\right)$;

$C_{\mathrm{w}}$ is the thermal capacity $\left(\mathrm{J} / \mathrm{kg}^{\circ} \mathrm{K}\right)$;

$\theta_{\mathrm{s}}$ is the melting temperature $\left({ }^{\circ} \mathrm{C}\right)$;

$\theta_{\mathrm{u}}$ is the ambient temperature $\left({ }^{\circ} \mathrm{C}\right)$;

$c_{\mathrm{s}}$ is the latent heat of melting $(\mathrm{J} / \mathrm{kg})$.

Basically, the charge to be considered is the sum of the charge of the return stroke and the lightning continuing current. Laboratory experience has revealed that the effects of the return stroke charge may be of minor importance when compared to the effects of the continuing current [11].

If a section of a tank receives a lightning discharge, the resulting current will heat the attachment point. If the metal is homogeneous, the current will heat a hemispherical volume [7]. The melted volume on the attachment point is calculated by (6), using the charge value provided by Monte Carlo simulation. In this way, the vessel puncture is assessed by the comparison between the radius of the hemispherical melted volume and the wall thickness. By using an expression analogous to (3), in which $n(t)$ is replaced by the number of events that cause a puncture in tank $t$, the expected annual number of punctures in each tank is finally estimated.

\section{APPLICATION EXAMPLE}

In the following, a case-study of realistic complexity relevant to an oil storage plant is described, in order to illustrate the various aspects of the proposed procedure.

The application example makes reference to the 27tanks storage plant, the top view of which is shown in Fig. 2. The geometrical characteristics of each tank are given in Table II.
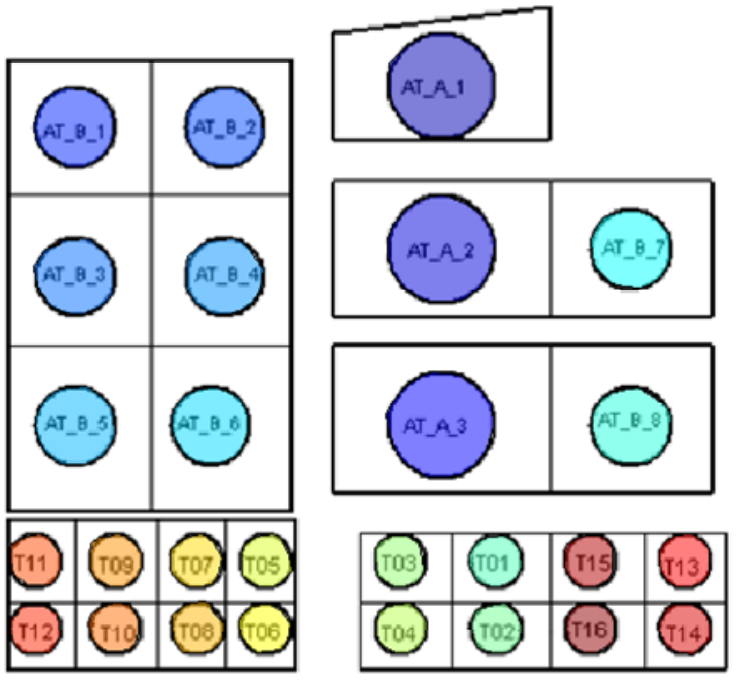

$15 \mathrm{~m}$

Fig. 2 - Top view of the considered oil plant.

Table II - Dimensions of the structures of Fig. 2.

\begin{tabular}{c|c|c|c|c}
\hline $\begin{array}{c}\text { Type of } \\
\text { Structure }\end{array}$ & $\begin{array}{c}\text { Volume } \\
\left(\mathrm{m}^{3}\right)\end{array}$ & $\begin{array}{c}\text { Height } \\
(\mathrm{m})\end{array}$ & $\begin{array}{c}\text { Diameter } \\
(\mathrm{m})\end{array}$ & $\begin{array}{c}\text { Thickness } \\
(\mathrm{mm})\end{array}$ \\
\hline AT_A_x & 1000 & 6 & 15 & 7 \\
\hline AT_B_x & 750 & 9 & 10.7 & 7 \\
\hline T0x & 250 & 7.5 & 7.5 & 5 \\
\hline
\end{tabular}

The first step of proposed approach is the Monte Carlo event generation and the application of the inception model (1) and (2). Fig. 3 shows the perspective stroke locations at ground of the direct strokes to a tank, obtained for 100000 events whose perspective stroke locations are uniformly distributed in an area $A$ of $1.7 \mathrm{~km}$. 


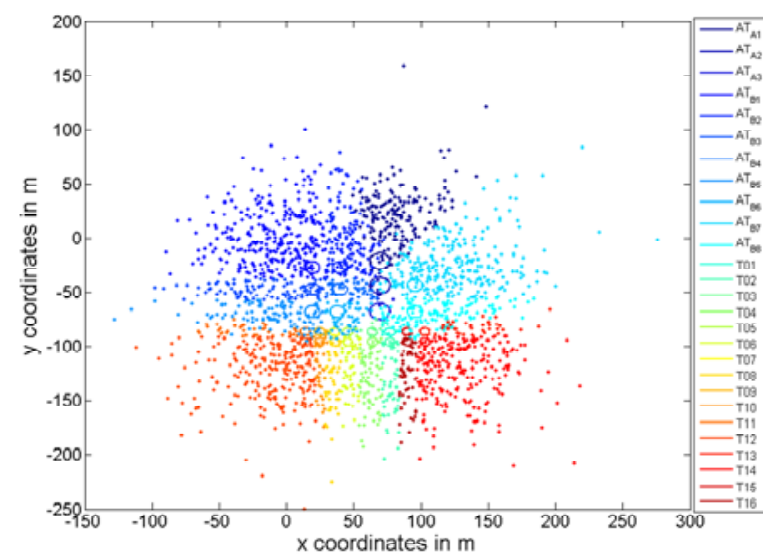

Fig. 3 - Top view the perspective stroke location of the Monte Carlo events that hit a tank of Fig. 2. Each stroke location is colored so to indicate a different affected tank.

Assuming $N_{\mathrm{g}}=3$ flashes $/ \mathrm{km} / \mathrm{yr}$, Fig. 4 shows the calculated expected annual number of direct strokes to one of the tanks. The figure also shows the same values obtained for reduced and enlarged distances between neighboring tanks by $25 \%$ with respect to the distances of Fig. 2.

To each event, the damage model described of (5) is applied, being known the $Q$ of the event and assuming the following values for the other parameters: $u_{\mathrm{a}, \mathrm{c}}=30 \mathrm{~V}$, $\gamma=8000 \mathrm{~kg} / \mathrm{m}^{3}, C_{\mathrm{W}}=500 \mathrm{~J} / \mathrm{kg}^{\circ} \mathrm{K}, \theta_{\mathrm{s}}=1500^{\circ} \mathrm{C}, \theta_{\mathrm{u}}=25^{\circ} \mathrm{C}$, $c_{\mathrm{s}}=0$. Table III shows the expected annual number of punctures for the three different cases analyzed in Fig. 4, namely the layout of Fig. 2 and for the cases of reduced and enlarged distances between neighboring tanks by $25 \%$. For the tanks not listed in the table, the calculation provides a zero expected number of punctures. The expected annual number equal to $0.0510^{-3}$ corresponds to one event that cause a puncture over the total number of 100000 events.

Table III - Expected annual number to punctures for the layout of Fig. 2 and for reduced and enlarged distances between neighboring tanks by $25 \%$.

\begin{tabular}{|c|c|c|c|}
\hline Tank & $\begin{array}{c}\text { Layout of } \\
\text { Fig. 2 }\end{array}$ & $\begin{array}{c}\text { Enlarged } \\
\text { distances }\end{array}$ & $\begin{array}{c}\text { Reduced } \\
\text { distances }\end{array}$ \\
\hline T02 & $0.10310^{-3}$ & $0.10510^{-3}$ & $0.10210^{-3}$ \\
\hline T04 & $0.05210^{-3}$ & 0 & $0.05110^{-3}$ \\
\hline T06 & 0 & $0.05210^{-3}$ & 0 \\
\hline T08 & $0.05210^{-3}$ & $0.05210^{-3}$ & $0.05110^{-3}$ \\
\hline T12 & $0.20710^{-3}$ & $0.21010^{-3}$ & $0.15310^{-3}$ \\
\hline T14 & $0.25810^{-3}$ & $0.26210^{-3}$ & $0.25510^{-3}$ \\
\hline
\end{tabular}

The results of Table III are justified by the fact that tanks of type T0x are those characterized by the lowest thickness value (as shown by Table II) and the tanks of the table are those characterized by higher level of expected annual number of direct strokes with respect to the other tanks of the same type.

The risk associated to the values of Table III does not take into account other effects that direct strokes to a tank may cause even without a perforation of the tank wall (e.g. the local thermal effects).

\section{INFLUENCE OF THE PRESENCE OF RODS AND WIRES}

In order to illustrate the effects of the presence of protecting rods and wires, we have repeated the calculation of the expected annual number of direct strokes and the expected annual number of punctures for the following three simple configurations:

a) four $20 \mathrm{~m}$ high rods at the corners of the area occupied by the tanks;

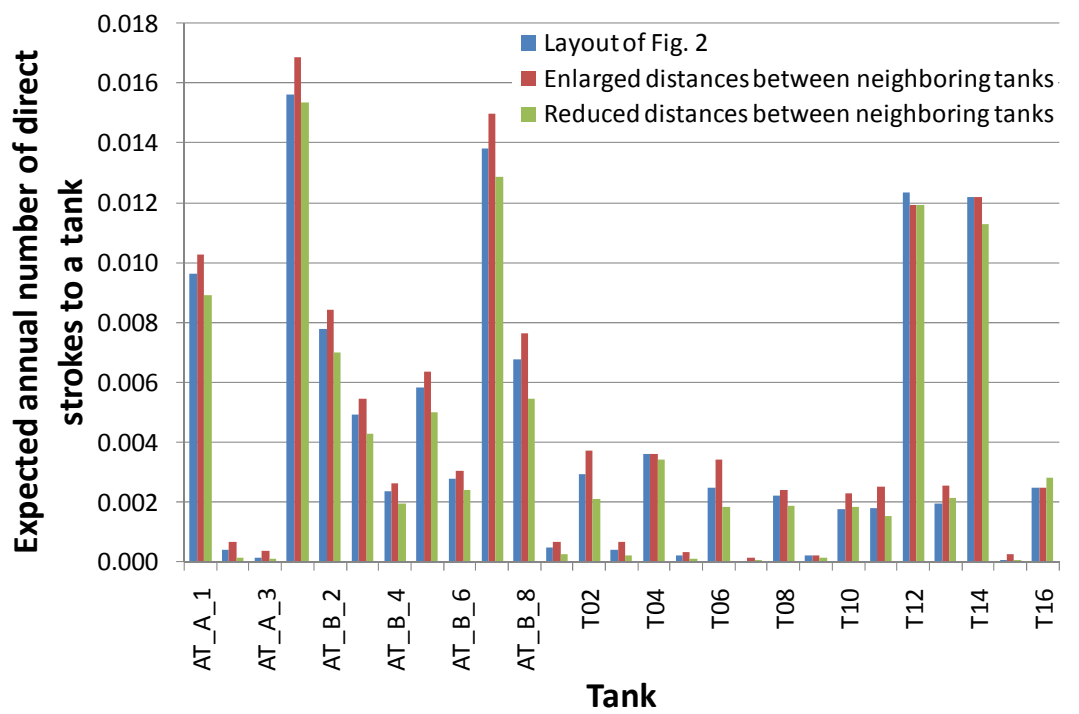

Fig. 4 - Expected annual number of direct strokes to one of the tanks for the layout of Fig. 2 and for reduced and enlarged distances between neighboring tanks by $25 \%$. 
b) additional rod in the middle of the area.

c) as case a) with additional four $15 \mathrm{~m}$ high overhead wires connecting the four rods and surrounding the area.

The calculation does not consider the possibility of a back flashover between the rods or wires and the tanks and neglects the presence the poles used to sustain the wires. Fig. 5 shows the perspective stroke location of the Monte Carlo events that hit a tank for each of the considered configurations. The corresponding expected number of direct strokes to each of the tanks is shown in Fig. 6.

For all of the considered cases with the addition of rods and wires, the calculation with 100 thousands of events does not show punctures.

If two additional wires that cross in the middle of the area are also included in configuration c), only for tank AT B 3 a non-null expected annual number of direct strokes is obtained $\left(0.05210^{-3}\right)$.

\section{CONCLUSIONS}

In this study a procedure for the assessment of the industrial risk due to lightning events is proposed.

The procedure is based on a Monte Carlo simulation and applies to each event both a lightning attachment mopdel and a damage calculation model. As the assumed models does not require a significant calculation effort, the simulation is carried out for 100 thousands of events. For the typical extension of indlustrial plants (few $\mathrm{km}^{2}$ ), such a number appears to be adequate to achieve an acceptable confidence level for the estimated annual number of direct strikes and damages.

The developed procedure requires a limited amount of additional data with respect to those used in a conventional risk analysis and allows the quantitative assessment of the risk due to lightning strikes on each equipment item. In particular, the capability to estimate the risk associate to severe scenarios triggered by lightning involving dangerous substances that may be present in chemical and process plants appears to be of peculiar importance.

The developed procedure appears to be able to incorporate different or more accurate damage models than the one relevant to the calculation of the number of
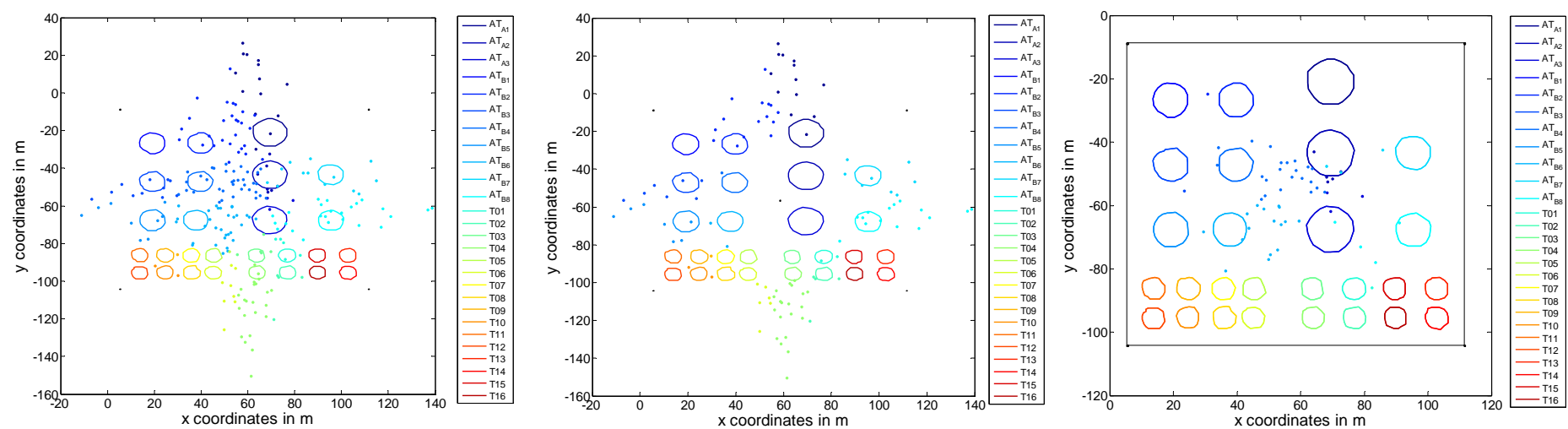

Fig. 5 - Top view the perspective stroke location of the Monte Carlo events that hit a tank of Fig. 2, from left to right: with four rods at the corners of the area occupied by the tanks; with an additional rod in the middle; with four surrounding overhead wires connecting four rods at the corners.

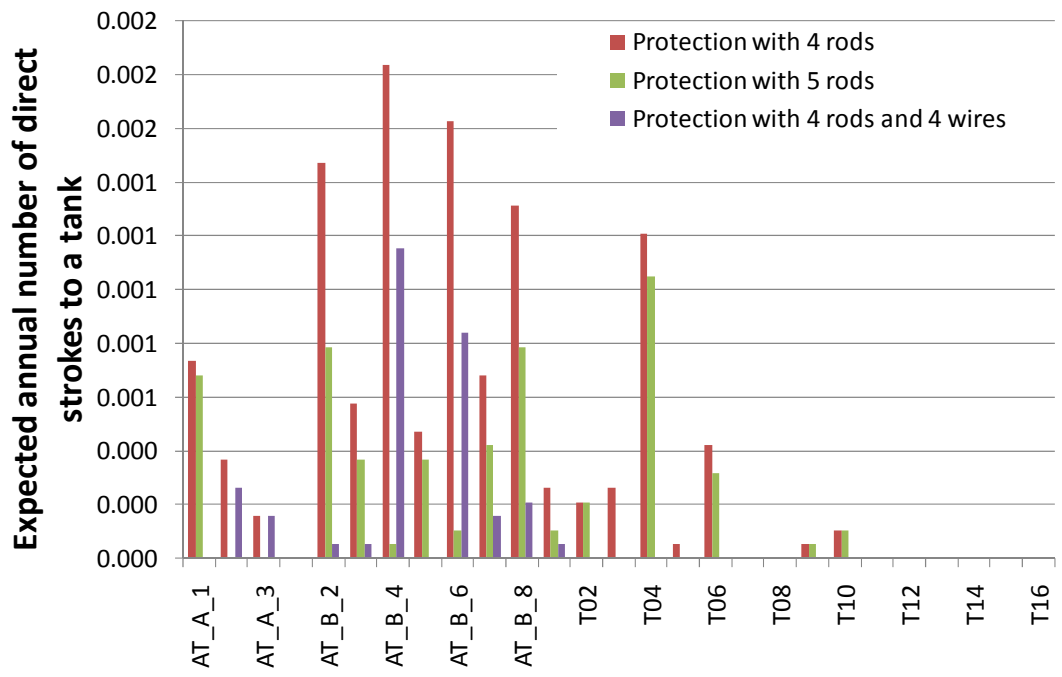

Tank

Fig. 6 - Expected annual number of direct strokes to one of the tanks for the layout of Fig. 2 for the considered three configurations of protecting rods and wires. 
punctures adopted in this paper, without a significant change of its structure.

\section{REFERENCES}

[1] US Enviromental Protection Agency, Lightning hazard to facilities handling flammable substances, EPA 550-F-97002c, 1997, www.epa.gov/ceppo.

[2] E. Renni, E. Krausmann, M. Campedel, V. Cozzani, Major Accident Due to the Impact of Natural Events on Technological Systems, 2nd International Conference on Risk Analysis and Crisis Response, Beijing, China, 2009.

[3] T. Horváth, "Computation of lightning protection, Research studies press LTD, 1991.

[4] Christian Bouquegneau, "Lightning protection of oil and gas industrial plants", IX International Symposium on Lightning Protection, Foz do Iguaçu, Brazil, 26th-30th November 2007.

[5] L.E. Gallego, O. Duarte, H. Torres, M. Vargas , J. Montaña, E. Pérez, J. Herrera, C. Younes, "Lightning risk assessment using fuzzy logic", Journal of Electrostatics, Vol. 60, No. 2-4, pp. 233-239, March 2004.

[6] A. Galván Diego, "A technical basis for guidance of lightning protection for offshore oil installations", Journal of Lightning Research, Vol. 3, pp. 1-9, 2007.

[7] E. Mariani, M. Rodriguez, "Controlling the risk of fire caused by hydrocarbon storage tanks", ICLP 2000, Rhodes, Greece, 18-22 Sept. 2000.

[8] C. Mazzetti, Z. Flisowski, "Analysis of the influence of different factors on the hazard for electronic systems due to lightning overvoltages", V SIPDA, V International Symposium on Lightning Protection Sao Paulo, Brazil, May 17-21, 1999.

[9] F. Fiamingo C. Mazzetti Z. Flisowski, "Smart building and lightning risk assessment: an approach to the protection of building automation systems high exposed to overvoltage failure", Proc. of 2003 IEEE Bologna PowerTech Conference, Bologna, Italy, June 23-26 2003.

[10] C. Buccella and A. Orlandi, "An efficient technique for the evaluation of lightning-induced voltage in a cylindrical vessel containing charged oil," IEEE Trans. Ind. Appl., vol. 39, no. 2, pp. 368-373, Mar./Apr. 2003.

[11] I. A. Metwally, F. Heidler, W. Zischank, "Measurement of the rear-face temperature of metals struck by lightning long-duration currents", European Transactions on Electrical Power, Euro. Trans. Electr. Power 2004; pp. 14:201-222.

[12] V. Cooray and M. Becerra, "Attachment of lightning flashes to grounded structures", Chapter 4 of the book Lightning protection, IET, Power and Energy Series 58, 2010.

[13] American Petroleum Institute, Design and Construction of Large, Welded, Low-Pressure Storage Tanks, pp. 196, 1990.

[14] American Petroleum Institute, Welded Steel Tanks for Oil Storage, pp. 376, 1988.

[15] National Fire Protection Association, Flammable and Combustible Liquids Code, pp. 140, 2008.

[16] John Wiley \& Sons, Model Code of Safe Practice in the Petroleum Industry: Refining Safety Code Pt. 3, pp. 156, June 1981.

[17] F.P. Lees, Loss Prevention in the process industries, II Ed.,
Butterworth-Heinemann, Oxford (UK), 1996.

[18] A. Borghetti, C. A. Nucci, M. Paolone, "An improved procedure for the assessment of overhead line indirect lightning performance and its comparison with the IEEE Std. 1410 method", IEEE Trans. on Power Delivery, pp. 684-692, January 2007.

[19] R. B. Anderson and A. J. Eriksson, "Lightning parameters for engineering application," Electra, vol. 69, pp. 65-102, 1980.

[20] Cigré Working Group 01 of SC 33, Guide to Procedures for Estimating the Lightning Performance of Transmission Lines Cigré, ref. no. 63, Oct. 1991.

[21] IEEE Working Group on the lightning performance of distribution lines, "Guide for improving the lightning performance of electric power overhead distribution lines", IEEE Std 1410, 2004.

[22] CIGRE Task Force 33.01.03, "Lightning exposure of structures and interception efficiency of air terminals," 118. Oct. 1997.

[23] M. Becerra, V. Cooray, F. Roman, "Lightning striking distance of complex structures", IET Generation, Transmission and Distribution, Vol. 2, No. 1, pp. 131-138, 2008.

[24] S. Ait-Amar, G. Berger, "A Modified Version of the Rolling Sphere Method", IEEE Trans. on Dielectrics and Electrical Insulation, Vol. 16, No. 3, pp. 718 - 725, 2009.

[25] F. A.M. Rizk, "Modeling of Lightning Exposure of Buildings and Massive Structures", IEEE trans. on Power Delivery, No. 4, pp. 1987 - 1998, 2009.

[26] V. Cooray, V. Rakov, N. Theethayi, "The lightning striking distance-Revisited", Journal of Electrostatics, Vol. 65, pp. 296-306, 2007.

[27] CEI EN 62305-2, Protection against lightning: Risk Management, 2006. 